\title{
Tratamentos estéticos utilizados para controle da oleosidade de pele
}

\author{
Aesthetic treatments used to control skin oil \\ Tratamientos estéticos utilizados para controlar el aceite de la piel \\ Suelen Figura Milani', João Luiz Coelho Ribas ${ }^{1 *}$.
}

\begin{abstract}
RESUMO
Objetivo: Descrever quais são os principais tratamentos para oleosidade de pele, bem como, analisar a eficiência e se há ou não a necessidade de novos protocolos e tratamentos para essa disfunção. Métodos: Trata-se de uma pesquisa integrativa da literatura onde foi realizado uma pesquisa nas bases de dados como Biblioteca Virtual em Saúde (BVS), PubMed, Scielo e Science direct, utilizando os seguintes critérios de inclusão: artigos que estejam dentre os anos de 2000 a 2020. Os idiomas selecionados foram português, espanhol e inglês. A partir dessa pesquisa, se utilizou um total de 31 artigos para a escrita do artigo. Resultados: Para o tratamento de oleosidade, as alternativas são o uso de ativos tópicos, ácidos e os tratamentos estéticos feitos em consultório com uso de agulha ou equipamentos. Foi possível observar, que há tratamentos para oleosidade de pele, porém, não apresentam resultados com efetividade significativa. Considerações finais: Os tratamentos mais utilizados na atualidade são os de uso tópico, como ácidos ou ativos. Além disso, observamos que a toxina botulínica é uma opção de tratamento que ainda se encontra em estudo, mas que pode se tornar uma ótima opção para tratamento direto da glândula sebácea.
\end{abstract}

Palavras-chave: Anormalidades da pele, Toxinas botulínicas tipo A, Uso off-label.

\begin{abstract}
Objective: To describe the main treatments for skin oils, as well as to analyze the efficiency and whether or not there is a need for new protocols and treatments for this dysfunction. Methods: It is an integrative literature search where a search was carried out in databases such as Virtual Health Library (BVS), PubMed, Scielo and Science direct, using the following inclusion criteria: articles that are among the years of 2000 to 2020 . The selected languages were Portuguese, Spanish and English. From this research, a total of 31 articles were used to write the article. Results: For the treatment of greasiness, the alternatives are the use of topical assets, acids and aesthetic treatments done in the office using a needle or equipment. It was possible to observe that there are treatments for skin oils, however, they do not present results with significant effectiveness. Considerations finales: The treatments most used today are those of topical use, as acids or actives. In addition, we observed that botulinum toxin is a treatment option that is still under study, but that can become a great option for direct treatment of sebaceous gland.
\end{abstract}

Keywords: Skin abnormalities, Botulinum toxins type A, Off-label' use.

\section{RESUMEN}

Objetivo: Describir los principales tratamientos para los aceites cutáneos, así como analizar la eficacia y si existe o no la necesidad de nuevos protocolos y tratamientos para esta disfunción. Métodos: Se trata de una búsqueda bibliográfica integradora donde se realizó una búsqueda en bases de datos como Virtual Health

1Universidade Positivo (UP), Curitiba - PR. *E-mail: jlcribas@yahoo.com.br 
Library (BVS), PubMed, Scielo y Science direct, utilizando los siguientes criterios de inclusión: artículos que se encuentran entre los años de 2000 a 2020. Los idiomas seleccionados fueron portugués, español e inglés. De esta investigación, se utilizaron un total de 31 artículos para escribir el artículo. Resultados: Para el tratamiento de la untuosidad, las alternativas son el uso de activos tópicos, ácidos y tratamientos estéticos realizados en el consultorio mediante aguja o equipo. Se pudo observar que existen tratamientos para aceites cutáneos, sin embargo, no presentan resultados con efectividad significativa. Consideraciones finales: Los tratamientos más utilizados en la actualidad son los de uso tópico, como ácidos o activos. Además, observamos que la toxina botulínica es una opción de tratamiento que aún está en estudio, pero que puede convertirse en una gran opción para el tratamiento directo de glándula sebácea.

Palabras clave: Anomalías cutáneas, Toxinas botulínicas tipo A, Uso off-label.

\section{INTRODUÇÃO}

A pele é o maior órgão do corpo humano, que recobre a sua superfície e tem função de barreira, proteção, controle de perda de água, proteção contra radiação solar. Este órgão, está em contato direto com o ambiente, e sofre diretamente com as ações na rotina e no cotidiano. Qualquer alteração, seja na função ou até mesmo na estética da pele, tem como consequência problemas para a saúde física e mental do indivíduo em questão e por esse motivo, a preocupação com a estética aumentou muito na última década. A manutenção da viscosidade, integridade e aspecto da pele, vem se tornando cada vez mais uma procura constante em todo o mundo (CAMPOS MPMBG, et al., 2019; EICHENFIELD LF, et al., 2010).

A pele apresenta dois tecidos principais, o tecido epidérmico, sendo o mais superficial, e a derme, sendo um tecido de maior extensão e profundidade, constituído estruturas importantes, como: pelos, glândulas (sebáceas e sudoríparas) e unhas. As glândulas sebáceas, que são as responsáveis pela oleosidade na pele, também estão presentes na derme. As glândulas sebáceas são alveolares e vários desses alvéolos desembocam em um ducto curto, onde sua luz está presente várias gotículas de lipídios. A secreção sebácea é uma mistura complexa de lipídios, que possui em sua mistura, triglicerídeos, ácidos graxos livres, colesterol e ésteres. As glândulas sebáceas encontram-se em toda a pele, à exceção das regiões palmoplantares (CAMPOS MPMBG, et al., 2019; ROH M, 2006, VOEGELI R, et al., 2019).

A oleosidade é caracterizada pela formação em excesso do conteúdo presente dentro das glândulas sebáceas, mais conhecido como sebo. As glândulas sebáceas têm sua ação controlada por andrógenos, principalmente a testosterona, que induzem a produção do sebo, uma mistura complexa e variável de lipídeos. O sebo consegue atingir a superfície da pele passando pelo infundíbulo, que é uma porção da glândula sebácea responsável pela secreção do seu conteúdo (KIM B, et al., 2011; LEE DY, et al., 2008; LI ZJ, et al., 2013; LI X, et al., 2017).

A função do sebo, é retardar a perda de água e manter a hidratação da pele e também do pelo, visto que a glândula sebácea está juntamente com o folículo piloso, formando o folículo pilossebaceo. Porém, essa produção quando de forma exarcebada, produz a conhecida oleosidade na pele, favorecendo o aparecimento não só da oleosidade como também da acne, que tende a ocorrer com maior frequência em regiões como na face, no tronco e no peito devido ao maior número de glândulas sebáceas presente nestas $(\mathrm{ROH} M, 2006$; VOEGELI R, et al., 2019)

O nível de oleosidade depende do nível da gordura que é produzida pela glândula sebácea. Além disso, a produção das glândulas é diretamente influenciada pela ação do sol, vento, poeira, poluição, alimentação, rotina de cuidados, excesso de ressecamento, idade, quantidade hormonal e fototipo. A pele ressecada por exemplo, faz um mecanismo que induz a produção de sebo, já que a pele entende que necessita do sebo para hidratar esse tecido ressecado (HASSUN KA, 2000; KHAN H, et al., 2016; KIM B, et al., 2011; LEE DY, et al., 2008; LI ZJ, et al., 2013; LI X, et al., 2017).

A necessidade de conhecimento dos profissionais da saúde perante esse tema, tendo amplo conhecimento de quais são as opções que temos de acordo com os tratamentos. Além de enfatizar a importância da pesquisa no âmbito estético, na procura de inovação e criação de novos tratamentos e 
protocolos, de maior efetividade, durabilidade e custo-benefício aos indivíduos que fazem uso desses tratamentos (LEE DY, et al., 2008; LI ZJ, et al., 2013; LI X, et al., 2017; ROH M, 2006, VOEGELI R, et al., 2019).

O objetivo desse trabalho é descrever quais são os principais tratamentos para oleosidade de pele, bem como, analisar a eficiência e se há ou não a necessidade de novos protocolos e tratamentos para essa disfunção.

\section{MÉTODOS}

Para realização deste trabalho, foi realizado uma revisão bibliográfica, onde os artigos e trabalhos para sua execução foram encontrados nas seguintes bases de dados: BVS, PubMed, Scielo e Science direct. Os descritores utilizados foram: Oleosidade, pele oleosa, estética, luz intensa pulsada, ácido mandélico, ácido salicílico, niacinamida, microagulhamento e toxina botulínica.

Os critérios de inclusão foram artigos com estudo humanos ou revisões bibliográficas que estejam dentre os anos de 2000 a 2020. Os idiomas selecionados foram português, espanhol e inglês. Ao todo, foi encontrado 78 artigos em todas as bases de dados pesquisadas com as palavras-chave e critérios de inclusão acima.

\section{RESULTADOS}

Após a leitura de todos os resumos, foram selecionados e utilizados 31 artigos, que tinham relevância de acordo com o tema e respondiam os objetivos do presente trabalho (Quadro 1). 


\section{Revista Eletrônica Acervo Saúde / Electronic Journal Collection Health | ISSN 2178-2091}

Quadro 1 - Quadro ilustrativo de artigos utilizados.

\begin{tabular}{|c|c|c|c|}
\hline Autores & Título & Objetivo & Conclusão \\
\hline $\begin{array}{l}\text { BERTOSSE D, et } \\
\quad \text { al., } 2019\end{array}$ & $\begin{array}{l}\text { O tratamento associado ao } \\
\text { rejuvenescimento da pele - } \\
\text { Laser Fraxel, Microbotox e } \\
\text { ácido hialurônico de baixo G } \\
\text { prime: resultados preliminares. }\end{array}$ & $\begin{array}{l}\text { O objetivo deste estudo é demonstrar } \\
\text { que a combinação dessas três técnicas } \\
\text { é melhor do que o tratamento único e } \\
\text { sua associação pode impulsionar a } \\
\text { melhoria da textura e qualidade da pele } \\
\text { para rejuvenescer o rosto do paciente. }\end{array}$ & $\begin{array}{l}\text { Neste estudo, demonstramos que o uso de três tratamentos } \\
\text { juntos, como mBTX, Volite e laser fracionário, um resultado } \\
\text { melhor apesar de cada técnica sozinha. }\end{array}$ \\
\hline $\begin{array}{l}\text { CAMPOS } \\
\text { MPMBG, et al., } \\
2019\end{array}$ & $\begin{array}{l}\text { Uso de técnicas avançadas de } \\
\text { imagem para a caracterização } \\
\text { da pele oleosa. }\end{array}$ & $\begin{array}{l}\text { O objetivo deste estudo foi avaliar as } \\
\text { características cutâneas decorrentes da } \\
\text { produção excessiva de sebo, por meio } \\
\text { de técnicas avançadas de análise de } \\
\text { imagens de pele, bem como verificar a } \\
\text { correlação das diferentes propriedades } \\
\text { em distintas regiões faciais. }\end{array}$ & $\begin{array}{l}\text { Podemos concluir que diferentes regiões faciais apresentam } \\
\text { características distintas relacionadas à oleosidade e à } \\
\text { quantificação e aparecimento de poros e comedões. }\end{array}$ \\
\hline $\begin{array}{l}\text { DRAELOS ZD, et } \\
\quad \text { al., 2006) }\end{array}$ & $\begin{array}{l}\text { O efeito da niacinamida a } 2 \% \text { na } \\
\text { produção de sebo facial. }\end{array}$ & $\begin{array}{l}\text { Demonstrar o efeito da niacinamida a } \\
2 \% \text { tópica nas taxas de excreção de } \\
\text { sebo e produção de sebo casual em } \\
\text { populações orientais e caucasianos. }\end{array}$ & $\begin{array}{l}\text { A niacinamida a } 2 \% \text { tópica pode ser eficaz na redução do SER } \\
\text { em indivíduos japoneses e CSL em indivíduos caucasianos. }\end{array}$ \\
\hline $\begin{array}{l}\text { DRESSLER D, et } \\
\quad \text { al., 2005) }\end{array}$ & $\begin{array}{l}\text { Toxina botulínica - Mecanismos } \\
\text { de ação. }\end{array}$ & $\begin{array}{l}\text { Esta revisão descreve mecanismos } \\
\text { terapeuticamente relevantes de ação da } \\
\text { toxina botulínica (BT). O modo de ação } \\
\text { molecular da BT inclui a ligação } \\
\text { extracelular a estruturas glicoproteicas } \\
\text { nos terminais nervosos colinérgicos e o } \\
\text { bloqueio intracelular da secreção de } \\
\text { acetilcolina. }\end{array}$ & $\begin{array}{l}\text { Os efeitos indiretos no sistema nervoso central incluem inibição } \\
\text { reflexa, normalização da inibição recíproca, inibição intracortical } \\
\text { e potenciais evocados somatossensoriais. A redução da dor } \\
\text { induzida por formalina sugere efeitos analgésicos diretos da BT, } \\
\text { possivelmente mediados pelo bloqueio da substância P, } \\
\text { glutamato e peptídeo relacionado ao gene da calcitonina. }\end{array}$ \\
\hline $\begin{array}{l}\text { HASSUN KA, } \\
2000\end{array}$ & Acne: etiopatogenia. & $\begin{array}{l}\text { Analisar a etiopatogenia da acne e } \\
\text { analisar fatores agravantes. }\end{array}$ & $\begin{array}{l}\text { Vários aspectos da patogênese da acne ainda permanecem } \\
\text { desconhecidos, porém os novos modelos experimentais de } \\
\text { cultura de sebócitos } 43 \text { e a manutenção da função das glândulas } \\
\text { sebáceas in vitro } 44 \text { são métodos. }\end{array}$ \\
\hline $\begin{array}{l}\text { MADAN RK e } \\
\text { LEVITT J, } 2014\end{array}$ & $\begin{array}{l}\text { Uma revisão da toxicidade das } \\
\text { preparações de ácido salicílico } \\
\text { tópico. }\end{array}$ & $\begin{array}{l}\text { Revisão sobre a toxicidade do ácido } \\
\text { salicílico em soluções tópicas. }\end{array}$ & $\begin{array}{l}\text { Estudos formais de dose-resposta e toxicidade são necessários } \\
\text { para estabelecer a dose máxima segura de ácido salicílico, } \\
\text { particularmente para pacientes com barreira cutânea } \\
\text { prejudicada. Deve-se ter cuidado especial ao prescrever ácido } \\
\text { salicílico tópico para condições que envolvem grandes áreas de } \\
\text { superfície corporal, como psoríase e ictiose, e para crianças. }\end{array}$ \\
\hline
\end{tabular}




\section{Revista Eletrônica Acervo Saúde / Electronic Journal Collection Health | ISSN 2178-2091}

\begin{tabular}{|c|c|c|c|}
\hline Autores & Título & Objetivo & Conclusão \\
\hline Li ZJ, et al., 2013 & $\begin{array}{l}\text { Regulação da produção de } \\
\text { lipídios pela sinalização da } \\
\text { acetilcolina nas glândulas } \\
\text { sebáceas humanas. }\end{array}$ & $\begin{array}{l}\text { Nós investigamos o papel da sinalização } \\
\text { da acetilcolina nas glândulas sebáceas } \\
\text { usando sebócitos humanos e um estudo } \\
\text { clínico usando toxina botulínica. }\end{array}$ & $\begin{array}{l}\text { Esses resultados fornecem evidências de que a sinalização da } \\
\text { acetilcolina desempenha um papel significativo na biologia da } \\
\text { glândula sebácea humana e identificam a sinalização da } \\
\text { acetilcolina como um alvo promissor no manejo clínico de } \\
\text { distúrbios em que a produção de sebo é aumentada, como acne } \\
\text { vulgar. }\end{array}$ \\
\hline $\begin{array}{l}\text { MIN P, et al., } \\
2015\end{array}$ & $\begin{array}{l}\text { Alteração da produção de sebo } \\
\text { após injeções de toxina } \\
\text { botulínica tipo A para o } \\
\text { tratamento de rítides na testa: } \\
\text { uma investigação clínica } \\
\text { comparativa de dose dupla- } \\
\text { cega prospectiva } \\
\text { randomizada. }\end{array}$ & $\begin{array}{l}\text { Investigamos prospectivamente a } \\
\text { regulação do sebo e seu gradiente ao } \\
\text { redor do local da injeção em pacientes } \\
\text { que receberam injeções intramusculares } \\
\text { de toxina botulínica A (BTX-A) para } \\
\text { ritides frontais, comparando duas doses } \\
\text { de injeção. }\end{array}$ & $\begin{array}{l}\text { A injeção intramuscular de BTX-A reduz significativamente a } \\
\text { produção de sebo no local da injeção, mas aumenta a produção } \\
\text { de sebo da pele ao redor em um raio de } 2,5 \mathrm{~cm} \text { nas } 2,4 \text { e } 8 \\
\text { semanas de acompanhamento. }\end{array}$ \\
\hline $\begin{array}{l}\text { SOMA Y, et al., } \\
2005\end{array}$ & $\begin{array}{l}\text { Efeitos hidratantes da } \\
\text { nicotinamida tópica na pele } \\
\text { seca atópica. }\end{array}$ & $\begin{array}{l}\text { Examinou o efeito da nicotinamida } \\
\text { tópica na pele seca atópica e comparou } \\
\text { os resultados com o efeito da vaselina } \\
\text { branca em um estudo de comparação } \\
\text { esquerda-direita. }\end{array}$ & $\begin{array}{l}\text { O creme de nicotinamida é um hidratante mais eficaz do que a } \\
\text { vaselina branca na pele atópica seca e pode ser usado como um } \\
\text { coadjuvante no tratamento da dermatite atópica. }\end{array}$ \\
\hline $\begin{array}{l}\text { TANNO O, et al., } \\
2000\end{array}$ & $\begin{array}{l}\text { A nicotinamida aumenta a } \\
\text { biossíntese de ceramidas, bem } \\
\text { como de outros lipídios do } \\
\text { estrato córneo, para melhorar a } \\
\text { barreira de permeabilidade } \\
\text { epidérmica. }\end{array}$ & $\begin{array}{l}\text { Neste estudo, investigou o papel da } \\
\text { nicotinamida } \\
\text { especialmente a relação entre a } \\
\text { nicotinamida e os lipídios do estrato } \\
\text { córneo. }\end{array}$ & $\begin{array}{l}\text { Em conclusão, mostramos que a nicotinamida aumenta a } \\
\text { biossíntese de lipídios intercelulares, como esfingolipídios } \\
\text { incluindo ceramida, glucosilceramida e esfingomielina, ácidos } \\
\text { graxos livres e colesterol em queratinócitos humanos em cultura. }\end{array}$ \\
\hline $\begin{array}{l}\text { VARGAS DCO, } \\
\text { et al., } 2018\end{array}$ & $\begin{array}{l}\text { Eficácia da toxina botulínica } A \\
\text { para o tratamento da síndrome } \\
\text { da dor na bexiga: uma revisão } \\
\text { sistemática. }\end{array}$ & $\begin{array}{l}\text { Para determinar a eficácia e segurança } \\
\text { da BTX-A, em comparação com outras } \\
\text { intervenções para o tratamento da BPS } \\
\text { para melhorar a qualidade de vida. }\end{array}$ & $\begin{array}{l}\text { Não há evidências suficientes para concluir a eficácia da BTX-A } \\
\text { no tratamento da cistite intersticial para melhorar a qualidade de } \\
\text { vida. }\end{array}$ \\
\hline $\begin{array}{l}\text { WOHLRAB J, et } \\
\quad \text { al., } 2014\end{array}$ & $\begin{array}{l}\text { Niacinamida - Mecanismos de } \\
\text { Ação e Seu Uso Tópico em } \\
\text { Dermatologia. }\end{array}$ & $\begin{array}{l}\text { Analisar mecanismo de ação da } \\
\text { niacinamida tópica. }\end{array}$ & $\begin{array}{l}\text { Em resumo, pode-se afirmar que a niacinamida possui } \\
\text { propriedades físico-químicas adequadas para aplicação tópica e } \\
\text { pode ser considerado seguro. }\end{array}$ \\
\hline $\begin{array}{l}\text { MURILLO RM, } \\
2011\end{array}$ & $\begin{array}{l}\text { Luz pulsada intensa: } \\
\text { aplicaciones en dermatologia. }\end{array}$ & $\begin{array}{l}\text { Detalhar quais as aplicações possíveis } \\
\text { utilizando o aparelho de luz intensa } \\
\text { pulsada. }\end{array}$ & $\begin{array}{l}\text { Conclui-se que a luz intensa pulsada é utilizada para: lesões } \\
\text { vasculares, } \quad \text { depilação, } \\
\text { fotorrejuvenescimento, acne. }\end{array}$ \\
\hline
\end{tabular}

\footnotetext{
REAS/EJCH | Vol.13(1) | e5550 | DOI: https://doi.org/10.25248/reas.e5550.2021 Página $\mathbf{5}$ de $\mathbf{1 4}$
} 


\section{Revista Eletrônica Acervo Saúde / Electronic Journal Collection Health | ISSN 2178-2091}

\begin{tabular}{|c|c|c|c|}
\hline Autores & Título & Objetivo & Conclusão \\
\hline $\begin{array}{l}\text { LOSIFIDIS C e } \\
\text { GOUTOS I, } 2019\end{array}$ & $\begin{array}{l}\text { Indução percutânea de } \\
\text { colágeno (microagulhamento) } \\
\text { para o tratamento de cicatrizes } \\
\text { não atróficas: revisão da } \\
\text { literatura. }\end{array}$ & $\begin{array}{l}\text { Revisão bibliográfica sobre os efeitos do } \\
\text { microagulhamento em cicatriz não } \\
\text { atrófica. }\end{array}$ & $\begin{array}{l}\text { As técnicas de agulhamento são adjuvantes promissores para o } \\
\text { tratamento de cicatrizes não atróficas. }\end{array}$ \\
\hline $\begin{array}{l}\text { EICHENFIELD } \\
\text { LF, et al., } 2010\end{array}$ & $\begin{array}{l}\text { Perspectivas sobre opções } \\
\text { terapêuticas para acne: uma } \\
\text { atualização. }\end{array}$ & $\begin{array}{l}\text { Este artigo fornece uma visão geral das } \\
\text { informações atuais sobre o tratamento } \\
\text { tópico e sistêmico da acne, incluindo } \\
\text { opções de entrega inovadoras e novas } \\
\text { formulações e combinações de } \\
\text { medications. }\end{array}$ & $\begin{array}{l}\text { A acne de início precoce parece ocorrer com mais frequência e } \\
\text { justifica aconselhamento e intervenção precoces. D }\end{array}$ \\
\hline $\begin{array}{l}\text { JACOBS SW e } \\
\text { CULBERTSON } \\
\quad \text { EJ, } 2018\end{array}$ & $\begin{array}{l}\text { Efeitos do tratamento tópico } \\
\text { com ácido mandélico na } \\
\text { viscoelasticidade da pele facial. }\end{array}$ & $\begin{array}{l}\text { Nosso interesse era elucidar seus } \\
\text { possíveis efeitos nas propriedades } \\
\text { físicas da pele. Aproveitamos nossa } \\
\text { experiência com o Cutômetro para } \\
\text { elucidar os efeitos da aplicação tópica de } \\
\text { ácido mandélico nas propriedades } \\
\text { mecânicas da pele da pálpebra inferior. }\end{array}$ & $\begin{array}{l}\text { Embora a documentação fotográfica continue a ser o padrão ouro } \\
\text { para avaliar os resultados clínicos dos tratamentos faciais, ela } \\
\text { não avalia adequadamente as mudanças objetivas na qualidade } \\
\text { da pele. Os parâmetros viscoelásticos da pele facial podem ser } \\
\text { medidos de forma rápida, fácil e indolor em tempo real usando } \\
\text { um Cutômetro, embora haja um custo associado de aquisição e } \\
\text { manutenção do dispositivo. }\end{array}$ \\
\hline $\begin{array}{l}\text { ZAHOOR M, et } \\
\quad \text { al., } 2019\end{array}$ & $\begin{array}{l}\text { Isolamento de quercetina e } \\
\text { ácido mandélico de frutos de } \\
\text { Aesculus indica e suas } \\
\text { atividades biológicas. }\end{array}$ & $\begin{array}{l}\text { A presente investigação levou ao } \\
\text { isolamento de dois compostos relatados } \\
\text { que foram isolados pela primeira vez da } \\
\text { fruta Aesculus indica. Para análise de } \\
\text { atividades biológicas. }\end{array}$ & $\begin{array}{l}\text { Os extratos da fruta Aesculus indica apresentaram potencial } \\
\text { antioxidante e inibitório da anticolinesterase. Dois compostos } \\
\text { bioativos foram isolados na forma pura da fração de acetato de } \\
\text { etila. A partir dos resultados concluiu-se que o fruto desta planta } \\
\text { pode ser usado para minimizar o estresse oxidativo causado por } \\
\text { espécies reativas de oxigênio. }\end{array}$ \\
\hline $\begin{array}{l}\text { VAYALIL PK, et } \\
\text { al., } 2004\end{array}$ & $\begin{array}{l}\text { Os polifenóis do chá verde } \\
\text { previnem o dano oxidativo } \\
\text { induzido pela luz ultravioleta e a } \\
\text { expressão de } \\
\text { metaloproteinases de matriz na } \\
\text { pele de camundongo. }\end{array}$ & $\begin{array}{l}\text { Analisar a ação antiinflamatória do chá } \\
\text { verde. }\end{array}$ & $\begin{array}{l}\text { Como o chá verde e o EGCG têm múltiplos alvos e atuam de } \\
\text { maneira pleiotrópica, podemos considerar seu uso para melhorar } \\
\text { a qualidade de vida em pacientes com doenças inflamatórias. }\end{array}$ \\
\hline
\end{tabular}

REAS/EJCH | Vol.13(1) | e5550 | DOI: https://doi.org/10.25248/reas.e5550.2021

Página 6 de 14 


\section{Revista Eletrônica Acervo Saúde / Electronic Journal Collection Health | ISSN 2178-2091}

\begin{tabular}{|c|c|c|c|}
\hline Autores & Título & Objetivo & Conclusão \\
\hline $\begin{array}{l}\text { MAHMOOD T, et } \\
\quad \text { al., } 2010\end{array}$ & $\begin{array}{l}\text { Resultados da emulsão de } 3 \% \\
\text { de chá verde na produção de } \\
\text { sebo da pele em voluntários do } \\
\text { sexo masculino. }\end{array}$ & $\begin{array}{l}\text { Este estudo teve como objetivo } \\
\text { descrever os efeitos potenciais da } \\
\text { formulação estável (água em emulsão } \\
\text { de óleo), contendo } 3 \% \text { de extrato de chá } \\
\text { verde (Camellia sinensis L) na produção } \\
\text { de sebo da pele em voluntários humanos } \\
\text { saudáveis. }\end{array}$ & $\begin{array}{l}\text { Os resultados acima mencionados para formulação parecem } \\
\text { promover o conceito sobre os benefícios multifatoriais do chá } \\
\text { verde contra a produção de sebo. }\end{array}$ \\
\hline LI X, et al., 2017 & $\begin{array}{l}\text { Uma revisão do papel do sebo } \\
\text { no mecanismo da patogênese } \\
\text { da acne. }\end{array}$ & $\begin{array}{l}\text { Análise do papel do sebo na acne e } \\
\text { consequentemente seu prejuízo. }\end{array}$ & $\begin{array}{l}\text { Os estudos acima demonstram que as alterações nos } \\
\text { componentes específicos do sebo desempenham papéis } \\
\text { importantes no desenvolvimento da acne. }\end{array}$ \\
\hline $\begin{array}{l}\text { VOEGELI R, et } \\
\text { al., } 2019\end{array}$ & $\begin{array}{l}\text { Mapeamento da pele facial: da } \\
\text { avaliação bioinstrumental de } \\
\text { ponto único à visualização } \\
\text { contínua da hidratação da pele, } \\
\text { função de barreira, pH da } \\
\text { superfície da pele e sebo em } \\
\text { diferentes tipos de pele étnica. }\end{array}$ & $\begin{array}{l}\text { Este artigo revisa o histórico do } \\
\text { desenvolvimento e aplicação desta } \\
\text { metodologia. }\end{array}$ & $\begin{array}{l}\text { Uma nova abordagem de mapeamento p agrega mais valor à } \\
\text { compreensão das diferenças étnicas de pele. Esses estudos } \\
\text { mostram, inequivocamente, que não há relação entre a } \\
\text { pigmentação da pele e a função de barreira no rosto e que a } \\
\text { função de barreira da pele melhorada que está associada a } \\
\text { valores mais baixos de pH da superfície da pele não é } \\
\text { impulsionada pela melanina, pelo menos para indivíduos que } \\
\text { vivem na África do Sul. }\end{array}$ \\
\hline $\begin{array}{l}\text { KHAN H, et al., } \\
2016\end{array}$ & $\begin{array}{l}\text { Avaliação de Ascorbil Palmitato } \\
\text { (AP) e Ascorbil Fosfato de } \\
\text { Sódio (SAP) no Controle de } \\
\text { Sebo da Pele Facial em } \\
\text { Mulheres } \\
\text { Saudáveis. }\end{array}$ & $\begin{array}{l}\text { A presente investigação teve como } \\
\text { objetivo descrever a eficácia combinada } \\
\text { de AP e SAP para controlar o sebo facial } \\
\text { da pele por meio de uma emulsão } \\
\text { múltipla recém-formulada (W / O / W). }\end{array}$ & $\begin{array}{l}\text { O uso combinado de AP e SAP na formulação ativa (ME1) } \\
\text { proporcionou eficácia no controle da sebo da pele. Assim, os } \\
\text { efeitos da secreção anti-sebo do palmitato de ascorbil e do } \\
\text { ascorbil fosfato de sódio em mulheres adultas saudáveis } \\
\text { sugerem seu potencial promissor para pele oleosa indesejada, } \\
\text { redução da acne para embelezar a aparência facial e distúrbios } \\
\text { cutâneos associados causados por excreção elevada de sebo. }\end{array}$ \\
\hline $\begin{array}{l}\text { KIM B, et al., } \\
2011\end{array}$ & $\begin{array}{l}\text { Sebo, acne, elasticidade da } \\
\text { pele e diferença de gênero - } \\
\text { qual é o principal fator de } \\
\text { influência para os poros faciais? }\end{array}$ & $\begin{array}{l}\text { Avaliar a correlação entre os poros } \\
\text { faciais e possíveis fatores relacionais } \\
\text { como idade, sexo, secreção sebácea, } \\
\text { elasticidade da pele e presença de acne, } \\
\text { por meio de instrumentos objetivos de } \\
\text { bioengenharia. }\end{array}$ & $\begin{array}{l}\text { Homens, sebo aumentado e elasticidade da pele diminuída foram } \\
\text { principalmente correlacionados com o desenvolvimento dos } \\
\text { poros faciais. Novos estudos em população com vários perfis } \\
\text { demográficos e acne mais grave podem ser úteis para elucidar o } \\
\text { efeito potencial do envelhecimento e da gravidade da acne nos } \\
\text { poros faciais. }\end{array}$ \\
\hline
\end{tabular}




\section{Revista Eletrônica Acervo Saúde / Electronic Journal Collection Health | ISSN 2178-2091}

\begin{tabular}{|c|c|c|c|}
\hline Autores & Título & Objetivo & Conclusão \\
\hline $\begin{array}{l}\mathrm{ROH} \text { M, et al., } \\
2006\end{array}$ & $\begin{array}{l}\text { Saída de sebo como um fator } \\
\text { que contribui para o tamanho } \\
\text { dos poros faciais. }\end{array}$ & $\begin{array}{l}\text { Para avaliar a relação entre a produção } \\
\text { de sebo, idade, sexo, fatores hormonais } \\
\text { e gravidade da acne com o tamanho dos } \\
\text { poros. }\end{array}$ & $\begin{array}{l}\text { Tamanhos de poros aumentados estão associados com aumento } \\
\text { do nível de produção de sebo, idade e sexo masculino. Em } \\
\text { pacientes do sexo feminino, fatores hormonais adicionais, como } \\
\text { os do ciclo menstrual, afetam o tamanho dos poros. }\end{array}$ \\
\hline $\begin{array}{l}\text { LEE DY, et al., } \\
2008\end{array}$ & $\begin{array}{l}\text { Sebócitos expressam } \\
\text { peptídeos antimicrobianos de } \\
\text { catelicidina funcionais e podem } \\
\text { agir para matar } \\
\text { propionibacterium Acnes. }\end{array}$ & $\begin{array}{l}\text { Para determinar mais precisamente o } \\
\text { massa e sequência da catelicidina } \\
\text { peptídeo, sebócitos SZ95 foram } \\
\text { avaliados por dessorção / ionização a } \\
\text { laser intensificada por superfície - tempo } \\
\text { de voo - massa espectrometria com } \\
\text { anticorpo anti-LL37 capturar. }\end{array}$ & $\begin{array}{l}\text { A concentração real de b-defensinas, psoriasina ou outros } \\
\text { peptídeos antimicrobianos potenciais na glândula sebácea } \\
\text { permanece desconhecida, mas as descobertas atuais apóiam a } \\
\text { conclusão de que a glândula sebácea contribui para a defesa } \\
\text { epitelial pela liberação de várias moléculas antimicrobianas na } \\
\text { superfície da pele. }\end{array}$ \\
\hline $\begin{array}{l}\text { SARKAR R, et } \\
\text { al., } 2016\end{array}$ & $\begin{array}{l}\text { Avaliação Comparativa da } \\
\text { Eficácia e Tolerabilidade dos } \\
\text { Peelings Combinados de Ácido } \\
\text { Glicólico, Ácido Salicílico } \\
\text { Mandélico e Ácido Fítico em } \\
\text { Melasma. }\end{array}$ & $\begin{array}{l}\text { Comparar a eficácia terapêutica e } \\
\text { tolerabilidade do ácido glicólico (35\%) } \\
\text { versus ácido salicilmandélico (SM) } \\
\text { (ácido salicílico } 20 \% \text { / } 10 \% \text { mandélico) } \\
\text { versus peelings combinados fítico em } \\
\text { pacientes indianos com melasma. }\end{array}$ & $\begin{array}{l}\text { Conclui-se que os peelings com ácido GA (35\%) e SM são } \\
\text { igualmente eficazes e uma modalidade segura de tratamento } \\
\text { para melasma na pele indiana, além de serem mais eficazes do } \\
\text { que os peelings com ácido fítico. Os peelings salicilmandélicos } \\
\text { são mais bem tolerados e adequados para a pele indiana. }\end{array}$ \\
\hline $\begin{array}{l}\text { STEINSAPIR KD, } \\
\quad \text { et al., } 2015\end{array}$ & $\begin{array}{l}\text { Cosmético Microgotículas } \\
\text { Toxina Botulínica A Lift. }\end{array}$ & $\begin{array}{l}\text { Para investigar a segurança e eficácia } \\
\text { de uma microgotícula cosmética, toxina } \\
\text { botulínica periocular Um método que } \\
\text { trata extensivamente os depressores de } \\
\text { sobrancelha, mas não trata os } \\
\text { elevadores de sobrancelha. }\end{array}$ & $\begin{array}{l}\text { O método de elevação da sobrancelha em microgotículas } \\
\text { concentra com segurança o tratamento cosmético com toxina } \\
\text { botulínica ao longo da sobrancelha, pés de galinha e área } \\
\text { glabelar, resultando em um efeito de elevação da sobrancelha } \\
\text { que reduz as linhas da testa, eleva a sobrancelha e reduz o sulco } \\
\text { ao longo da sobrancelha. }\end{array}$ \\
\hline SHAR AR, 2008 & $\begin{array}{l}\text { Uso de toxina botulínica } \\
\text { intradérmica para reduzir a } \\
\text { produção de sebo e o tamanho } \\
\text { dos poros faciais. }\end{array}$ & $\begin{array}{l}\text { Revise o perfil de segurança e a eficácia } \\
\text { subjetiva da toxina botulínica } \\
\text { intradérmica do tipo A no tamanho dos } \\
\text { poros faciais e na produção de sebo. }\end{array}$ & $\begin{array}{l}\text { Dados preliminares sugerem que a toxina botulínica intradérmica } \\
\text { pode desempenhar um papel na redução da produção de sebo. } \\
\text { Um estudo quantitativo adicional pode ser necessário para } \\
\text { determinar os efeitos da toxina botulínica intradérmica no } \\
\text { tamanho dos poros. }\end{array}$ \\
\hline
\end{tabular}

Fonte: Milani SF e Ribas JLC, 2021.

$$
\overline{R E A S / E J C H ~|~ V o l .13(1) ~| ~ e 5550 ~ \mid ~ D O I: ~ h t t p s: / / d o i . o r g / 10.25248 / r e a s . e 5550.2021 ~ P a ́ g i n a ~} 8 \text { de } \mathbf{1 4}
$$




\section{DISCUSSÃO}

A oleosidade está presente na nossa pele devido a ação das glândulas sebáceas, que por sua vez, estão presentes no tecido dérmico e tem função biológica e de proteção. Sua principal função, é realizar a excreção de sebo para melhorar a lubrificação e impermeabilizar a pele e também os folículos pilosos. $O$ excesso dessa produção, é o que causa a oleosidade de pele (CAMPOS MPMBG, et al., 2019; HASSUN KA, 2000; EICHENFIELD LF, et al., 2010).

A oleosidade apresenta alguns sinais que causam desconforto ao paciente, como excesso de brilho, poros dilatados e até mesmo acne, principalmente na fase da adolescência. Sendo assim, há um impacto negativo na qualidade de vida nos indivíduos que possuem essas alterações. Os sinais deixados pela oleosidade, como aumento de poros e acne, podem persistir por muitos anos, permanecendo com o indivíduo desde a adolescência até a fase adulta (CAMPOS MPMBG, et al., 2019; HASSUN KA, 2000; EICHENFIELD LF, et al., 2010).

O folículo pilossebáceo tem em sua composição, a glândula e um pelo na sua estrutura. O canal presente do folículo pilossebáceo, é composto por uma parte distal que fica na superfície do epitélio e outra parte que fica entre os dois epitélios. As glândulas sebáceas têm em sua forma, uma quantidade significativa de lóbulos, onde cada um deles apresenta dois tipos celulares diferentes. Ao centro, encontramos células com vasto citoplasma e uma rede com quantidade grande de gordura, onde ficam os glicerídeos neutros. Já a região mais para a periferia, encontra-se células cúbicas basófilas que são as células germinativas. As secreções dessas glândulas, acontece quando a mesma é totalmente rompida, chamada de tipo holócrino (CAMPOS MPMBG, et al., 2019; LI X, et al., 2017).

Os tratamentos estéticos são limitados para o tratamento de oleosidade, porém, há opções que controlam e amenizam essa disfunção. Procedimentos invasivos, equipamentos e até mesmo ativos tópicos, são opções viáveis para a oleosidade. Isso porque, a pele, principalmente o tecido epidérmico e dérmico, é considerada excelente para entrega tópica, sem necessariamente precisar de um procedimento invasivo (EICHENFIELD LF, et al., 2010; KHAN H, et al., 2016; MAHMOOD T, et al., 2010; ROH M, 2006, VOEGELI R, et al., 2019).

As emulsões tópicas se espalham com uma boa aceitabilidade pelo usuário e são utilizadas como formulações dermatológicas estéticas há muito tempo. Em alguns casos, essas soluções podem melhorar procedimentos já realizados, ou até mesmo, atuar como principal tratamento (EICHENFIELD LF, et al., 2010; KHAN H, et al., 2016; MAHMOOD T, et al., 2010; ROH M, 2006, VOEGELI R, et al., 2019).

\section{Tratamentos utilizados: Ácidos}

\section{Ácido salicílico}

O ácido salicílico (AS) é um ácido 2-hidróxi-benzóico, sendo classificado com um beta-hidroxiácido, tendo três grupos interligados, um hidroxil, um carboxil e um anel de benzeno. O AS tem uma de suas origens da casca do salgueiro, é um ativo utilizado a mais de um século pela dermatologia. É um ácido com efeito mais controlado e tem efeito na camada mais superficial da pele, podendo ser realizado em qualquer fototipo (MADAN RK e LEVITT J, 2014).

O ácido salicílico causa bastante ardência na região, e não pode ser abanado, pois pode causar salicilismo, causando cefaleia, tontura e até problema de audição. Além disso, não se pode aplicar o AS em regiões muito extensas na região corporal (MADAN RK e LEVITT J, 2014).

AS tem ação em acne e em processos inflamatórios, sendo muito utilizado em pacientes com acne pustulosa ou não. Esse ácido também é conhecido por sua ação no sebo presente no folículo piloso produzido pelas glândulas sebáceas, dissolvendo de certa forma o sebo presente nos poros, que pioram significativamente a acne e a oleosidade (MADAN RK e LEVITT J, 2014; SARKAR R, et al., 2016).

A oleosidade é melhorada através deste mesmo efeito, o ácido se torna capaz de diminuir o óleo e o sebo produzido em excesso. Sendo assim, o AS não atua no mecanismo de ação da glândula, mas sim, no produto da mesma. O AS tem diversas finalidades, sendo uma substância queratoplástica, queratolítica, bacteriostática, tem ação antisséptica, onde é capaz de equilibrar produção de sebo. Seu mecanismo de ação, varia com a sua porcentagem e pH (SARKAR R, et al., 2016). 


\section{Ácido mandélico}

O ácido mandélico é um alfa-hidroxiácido pode ser encontrado em frutas e outros alimentos. Possui o maior peso molecular dentre os ácidos e por isso é indicado para pele negras. Além disso, o ácido mandélico é um derivado do extrato de amêndoas amargas, e tem seus resultados comprovados no tratamento e melhora da renovação da camada epidérmica, e também no tratamento de fotoenvelhecimento, acne e até mesmo hiperpigmentação. É um ácido que possui propriedades com ação bacteriostática e fungicida, sendo indicado no tratamento de acne e oleosidade (JACOBS SW e CULBERTSON EJ, 2018).

É uma opção de ácido para o tratamento de oleosidade, onde seu efeito é na queratinização da pele, melhorando o aspecto da pele no geral, inclusive a produção de sebo em excesso. Sua ação esfoliante permite a renovação celular, remoção de células mortas, eliminação de sebo superficial e melhora da oleosidade como consequência. Por ser um ácido de maior peso e menor penetração, seus resultados são visíveis de forma mais lenta que os demais, possuindo uma ação mais sutil e não tão agressiva (ZAHOOR M, et al., 2019).

Tem um processo de descamação lento e não tão ablativo, desta forma, a eliminação de células da camada córnea e eliminação do sebo de superfície também é lenta. Sendo um tratamento com número de sessões alto (em média 10 sessões) e que necessita de manutenção constante (JACOBS SW e CULBERTSON EJ, 2018; ZAHOOR M, et al., 2019).

\section{Tratamentos estéticos para controle de oleosidade}

\section{Toxina botulínica}

A toxina botulínica é uma ameaça à saúde humana a muitos séculos e mais ou menos há 5 décadas vem sendo utilizada para fins de saúde. A partir dos anos 2000 se deu início aos estudos e utilização da toxina botulínica para fins estéticos e a partir do seu uso se disseminou por todo o mundo. A toxina botulínica do tipo A é o sorotipo utilizado hoje no Brasil e em diversos países pelo mundo para o tratamento de saúde e melhora e atenuação de distúrbios estéticos (DRESSLER D, et al., 2005; VARGAS DCO e PERDÓMO HAG, et al., 2018; MIN P, et al., 2015).

A toxina botulínica é uma mistura de proteínas junto com a neurotoxina que é responsável pelo resultado e mecanismo de ação do produto. A toxina, se divide em uma cadeia leve e uma cadeia pesada, onde ambas são ligadas por ligação dissulfeto (VARGAS DCO e PERDÓMO HAG, et al., 2018; SHAR AR, 2018).

A neurotoxina botulínica existe em sete diferentes sorotipos denominados A, B, C, D, E, F e G. Sendo a toxina do tipo $A$ e do tipo $B$ as utilizadas para fins estéticos em países desenvolvidos. No Brasil, a toxina do tipo A é a comercializada para os profissionais da saúde (LI ZJ, 2013; VARGAS DCO e PERDÓMO HAG, et al., 2018, STEINSAPIR KD, et al., 2015).

A toxina botulínica tem sua ação motoneuronal a partir da inibição da liberação da acetilcolina. Para que a contração muscular ou a excreção de glândulas aconteça, a acetilcolina precisa ser liberada do terminal do axônio para a fenda pós-sináptica. Para que essa liberação ocorra, a vesícula pré-sináptica presente da fenda pré-sináptica, faz a endocitose da acetilcolina através da ação do complexo de proteína chamado SNARE (DRESSLER D, et al., 2005; LI ZJ, 2013).

A toxina atua clivando uma das proteínas desse grupo proteico, impedindo que a acetilcolina seja liberada para a fenda pós-sináptica. Quando a toxina é internalizada no músculo/derme (glândula), a toxina se liga a estruturas de glicoproteínas presentes dentro da vesícula pré-sináptica. Com isso, a toxina é quebrada, dividindo assim a cadeia pesada e a cadeia leve (DRESSLER D, et al., 2005; LI ZJ, 2013).

A cadeia pesada continua ligada na parte interna da vesícula, enquanto a cadeia leve vai para a parte externa da fenda e faz a clivagem de uma das proteínas do grupo SNARE, com isso, o complexo perde sua função e a liberação de acetilcolina não acontece por inativação da fusão das fendas (DRESSLER D, et al., 2005; LI ZJ, 2013). 
Quando o tecido alvo é um grupo muscular, ocorre paresia por denervação química, quando é uma glândula, a mesma perde sua função de secreção. Esse efeito é transitório pois o metabolismo acaba degradando a toxina botulínica e devolvendo a função ao complexo SNARE (DRESSLER D, et al., 2005; LI ZJ, 2013).

O efeito da toxina na glândula sebácea ainda é abstrato, pois até o momento não foi comprovado a relação da glândula sebácea com o receptor colinérgico e se a presença da acetilcolina realmente estimula a sua secreção e consequente destruição. Mesmo sem essa comprovação, estudos sugerem que a pele oleosa pode ser mais suscetível à regulação colinérgica do que a pele normal devido à maior abundância de sebócitos com mais receptores colinérgicos, porém, segundo alguns estudos esses achados podem ser respondidos por secreção das glândulas sudoríparas na mesma região ou até mesmo maior síntese de colágeno (MIN P, et al., 2015; LI ZJ, 2013; BERTOSSE D, et al., 2019).

\section{Luz intensa pulsada}

A luz intensa pulsada é um tratamento da atualidade bastante procurado em clínicas de estética para o tratamento de diversas disfunções estéticas. Isso porquê, o tratamento permite com que o paciente tenha sua rotina mantida ao término da sessão, além de ser um tratamento praticamente indolor e com resultados efetivos (BABILAS P, et al., 2010).

A luz pulsada é uma tecnologia policromática, não coerente e não colimada, com diversas espectros de luz, que permite o tratamento de diversas disfunções estéticas, atraves dos seus diversos comprimentos de ondas e cromóforos (BABILAS P, et al., 2010; MURILLO RM, 2011).

Cromóforo é conhecido como o alvo da luz pulsada, podendo ser vasos, porfirina (no caso da acne), colágeno e até mesmo a melanina. Seu comprimento de onda pode variar de 515 até $1200 \mathrm{~nm}$, além de ter uma variabilidade de filtros e controle de tempo de frequencia (BABILAS P, et al., 2010; MURILLO RM, 2011).

Já se conhece a efetividade da luz pulsada no tratamento da acne, e consequentemente, no tratamento da oleosidade também. Um dos mecanismos da luz pulsada quando o objetivo é o tratamento de acne e luz pulsada, é a fototérmólise no vasos sanguineos que irritam as glandulas sebaceas, diminuem drasticamente sua produção e excreção (MURILLO RM, 2011).

Como todo procedimento estético, a luz intensa pulsada possui algumas contraindicações, sendo elas: uso de retinoides, inclusive uso da isotretinoina, diabetes, hemofilia, implantes metálicos na região ou herpes simples ativa. Além de gestantes e lactantes que não podem realizar o procedimento (BABILAS P, et al., 2010; MURILLO RM, 2011).

\section{Microagulhamento}

A indução percutanea de colágeno ou microagulhamento, como é popularmente conhecido, é um procedimento realizado em consultório por profissionais habilitados. O procedimento se baseia no aumento da permeablidade dos ativos assim como a indução de colágeno atraves do processo de cicatrização do tecido epidérmico. O microagulhamento pode ser feito em diversas regiões do corpo inclusive no rosto. (FERNANDES D, 2004; LOSIFIDIS C e GOUTOS I, 2019).

O microagulhamento é um procedimento que não tem ação direta na glandula sebacea nem no sebo por ela produzido. Porém, o procedimento é utilizado para tratamento da oleosidade pela capacidade da técnica em favorecer a permeabilidade de qualquer ativo que for utilizado em sequencia (FERNANDES D, 2004).

O princípio básico do agulhamento é o repetitivo aplicação do dispositivo na pele, em múltiplas direções, sendo horizontal, vertical e obliquamente, até que seja atingido um sangramento pontual uniforme como um ponto final; o procedimento é repetido como necessário em intervalos variáveis (FERNANDES D, 2004). A eficácia do procedimento, baseia-se no estimulação de uma reação inflamatória e cicatrizante que é controlada e promove a remodelação do colágeno em virtude da liberação do fator de crescimento. Além disso, o microagulhamento promove uma lesão do tecido epidérmico atraves de suas microlesões, que proporciona uma maior permeabilidade a qualquer ativo (LOSIFIDIS C e GOUTOS I, 2019). 


\section{Ativos para oleosidade}

\section{Vitamina B3}

A niacinamida, também conhecida como nicotinamida, amida de ácido nicotínico, 3-piridinacarboxamida ou mais popularmente como vitamina B3 é um hidrofílico de substância endógena e pode ser encontrada tanto em plantas como em tecido animal. Ela possui propriedades antipruriginosa, antimicrobiana, vasoativa, foto-protetora, tem efeito clareador na pele de acordo com sua concentração e tem efeito sebostática nas glândulas sebáceas. A niacinamida é considerada uma substância bem tolerada quando utilizada em concentrações de $4 \%$ e utilizada com frequência em cosméticos para acne e pele oleosa (WOHLRAB J e KREFT D, et al., 2014).

A nicotinamida é uma das vitaminas do complexo $B$, e sua deficiência resulta em uma síndrome clínica chamada pelagra, que é caracterizada por dermatite, diarreia e até demência. A nicotinamida é necessária para a produção de nicotinamida adenina dinucleótido (NAD) e NAD fosfato (NADP), que atuam como coenzimas em mais de 40 reações bioquímicas (TANNO O, et al., 2000; WOHLRAB J e KREFT D, et al., 2014). Apesar de mecanismo responsável pela pelagra é obscura, deficiência de NAD ou NADP causada por deficiência da nicotinamida é pensado para resultar em pelagra. Os três sintomas aparecem com frequência na pelagra e é raro encontrar um caso comprovado sem dermatite. No entanto, o papel da nicotinamida na epiderme e por que a deficiência de nicotinamida resulta em dermatite não foi determinado até o momento (TANNO O, et al., 2000; WOHLRAB J e KREFT D, et al., 2014).

A ação da glândula sebácea é através da alteração do movimento do sebo produzido pela glândula sebácea, alterando assim o reservatório que no duto que liga a glândula sebácea a superfície da pele nos óstios foliculares, tendo um efeito sobre a esfoliação da pele que acontece com maior frequência, permitindo que o sebo seja eliminado. Esta deficiência causada no reservatório causou uma diminuição da excreção de sebo na superfície da pele (SOMA Y, et al., 2005; TANNO O, et al., 2000).

A niacinamida é uma vitamina dietética essencial para o corpo humano, tendo varios efeitos cutâneos, como melhora da acne vulgar, fotoenvelhecimento e até mesmo hiperpigmentação cutânea (SOMA Y, et al., 2005; WOHLRAB J e KREFT D, et al., 2014).

\section{Extrato glicólico de chá verde}

O chá verde, também conhecido como chá preto ou chá da china, pode ser utilizado de forma oral ou até mesmo de forma tópica. O chá verde utilizado topicamente, tem a capacidade de tratar a pele oleosa, pois diminui a atividade hormonal, tendo ativos inividores seletivos da 5 a-redutase. A 5 a-redutase, é uma enzima que faz a transformção de testosterona em dihidrotestosterona, sendo a forma ativa da mesma e que tem capacidade de se ligar a glândula sebacea e induzir sua secreção (VAYALIL PK, et al., 2004; MAHMOOD T, et al., 2010).

Além disso, o chá verde reduz a inflamação devido aos lipídios presentes no chá verde, como o ácido linoléico e o ácido a-linoléico, o que reduz o tamanho do microcomedônio na acne micrcomedonal. Adimais, também é conhecido sua atividade antimicrobiana, sendo um ativo bastante utilizado para tratamento de acne (VAYALIL PK, et al., 2004; MAHMOOD T, et al., 2010).

O composto mais importante presente no chá verde, é o galato de epigalocatequina, que pode ser encontrado na concentração de $40 \%$ a $50 \%$ no processamento da planta. Além disso, o chá verde possui polifenóis, que apresentam inúmeras propriedades biologicamente benéficas. $O$ ativo do chá verde tem ação anticarcinogênica, sendo também um antioxidante com grandes efeitos tissulares (OHISHI T, et al., 2016).

Abaixo segue o quadro com as especificações e caracteristicas dos tratamentos citados acima (Quadro 2). 


\section{Revista Eletrônica Acervo Saúde / Electronic Journal Collection Health | ISSN 2178-2091}

Quadro 2 - Tabela das caracteristicas dos tratamentos.

\begin{tabular}{|c|c|c|c|}
\hline Procedimento & Contraindicações & Vantagens & Desvantagens \\
\hline Ácido Salicilico & $\begin{array}{l}\text { Fototipo VI, } \\
\text { Alérgicos a salicílico, } \\
\text { Queloides, } \\
\text { Dermatites, } \\
\text { Rosáceas, } \\
\text { Gestantes } \\
\text { Lactantes }\end{array}$ & $\begin{array}{l}\text { Efeito direto na oleosidade; } \\
\text { Procedimento rápido; } \\
\text { Bons resultados. }\end{array}$ & $\begin{array}{l}\text { Ardência; } \\
\text { Salicilismo; } \\
\text { Irritabilidade; } \\
\text { Número alto de sessões; } \\
\text { Manutenção constante }\end{array}$ \\
\hline Ácido mandélico & $\begin{array}{l}\text { Dermatites, } \\
\text { Rosáceas, } \\
\text { Gestantes } \\
\text { Lactantes. }\end{array}$ & $\begin{array}{l}\text { Ácido seguro } \\
\text { Trata outras disfunções (como manchas) }\end{array}$ & $\begin{array}{l}\text { Número alto de sessões; } \\
\text { Não trata diretamente a oleosidade; } \\
\text { Efeito menos significativo }\end{array}$ \\
\hline Vitimina B3 & $\begin{array}{l}\text { Gestantes } \\
\text { Lactantes. }\end{array}$ & $\begin{array}{l}\text { Ativo com efeito sebostático; } \\
\text { Número baixo de contraindicações } \\
\text { Não causa irritabilidade. }\end{array}$ & $\begin{array}{l}\text { Quando utilizado sozinho demora para } \\
\text { visualizar os resultados. }\end{array}$ \\
\hline Extrato glicólico de chá verde & $\begin{array}{l}\text { Gestantes, } \\
\text { Lactantes, } \\
\text { Alérgico a substância. }\end{array}$ & $\begin{array}{l}\text { Ativo com efeito sebostático e poder } \\
\text { antioxidante } \\
\text { Número baixo de contraindicações; }\end{array}$ & $\begin{array}{l}\text { Quando utilizado sozinho demora para } \\
\text { visualizar os resultados. }\end{array}$ \\
\hline Toxina botulínica & $\begin{array}{l}\text { Alérgicos a ovo, } \\
\text { Problemas neurológicos graves, } \\
\text { Gestantes } \\
\text { Lactantes }\end{array}$ & $\begin{array}{l}\text { Resultados visíveis a curto prazo, } \\
\text { Uma ou duas sessões; } \\
\text { Pode ser feita em qualquer fototipo em quem } \\
\text { possui dermatite ou rosácea. }\end{array}$ & $\begin{array}{l}\text { Pode ficar com hematomas transitórios, } \\
\text { Uso de agulhas }\end{array}$ \\
\hline Luzintensa pulsada & $\begin{array}{l}\text { Fotipos acima de IV, } \\
\text { Pele bronzeada, } \\
\text { Dermatitite, } \\
\text { Queloides, } \\
\text { Cicatriz hipertrófica, } \\
\text { Uso de retinoides, } \\
\text { Herpes ativa, } \\
\text { Implantes metálicos }\end{array}$ & Pode tratar outras disfunções. & $\begin{array}{l}\text { Número alto de contraindicações } \\
\text { Tratamento longo; } \\
\text { Manutenção constante. }\end{array}$ \\
\hline Microagulhamento & $\begin{array}{l}\text { Fototipos acima de V, } \\
\text { Dermatite atópica, } \\
\text { Queloide, } \\
\text { Cicatriz hipertrófica, } \\
\text { Rosácea. }\end{array}$ & $\begin{array}{l}\text { Associações de ativos a escolha do } \\
\text { profissional } \\
\text { Trata outras disfunções, como } \\
\text { envelhecimento e manchas. }\end{array}$ & $\begin{array}{l}\text { Contraindicações; } \\
\text { Não trata oleosidade diretamente; } \\
\text { Pele sensível e machucados por alguns } \\
\text { dias. } \\
\text { Procedimento com desconforto } \\
\text { significativo. }\end{array}$ \\
\hline
\end{tabular}

Fonte: Milani SF e Ribas JLC, 2021. 


\section{CONSIDERAÇÕES FINAIS}

Foi possível observar que os tratamentos disponíveis para oleosidade através de procedimentos estéticos são bem limitados. Além disso, alguns dos procedimentos estéticos realizados, não tem ação direta da oleosidade, mas apenas um efeito secundário que favorece a sua redução. Foi possível analisar, que os tratamentos mais utilizados na atualidade são os de uso tópico, como ácidos ou ativos com ação sebostática. A toxina botulínica se mostrou um tratamento revolucionário e com bons resultados e perspectivas de novas descobertas, porém, ainda necessita de maiores estudos e formulação de protocolos e associações com efetividade e durabilidade comprovadas. Por fim, é notado a carência de novos tratamentos e investimentos no tratamento da oleosidade, além da necessidade da continuação de estudos e novos mecanismos de ação que ainda se apresentam desconhecidos.

\section{REFERÊNCIAS}

1. BABILAS P, et al. Intense pulsed light (IPL): A review. Lasers in Surgery and Medicine, 2010; 42(2), 93-104.

2. BERTOSSE D, et al. The skin rejuvenation associated treatment -Fraxel laser, Microbotox, and low $\mathrm{G}$ prime hyaluronic acid: preliminary results. Lasers in Medical Science. 2019. doi:10.1007/s10103-019-02738-z.

3. CAMPOS MPMBG, et al. Use of Advanced Imaging Techniques for the Characterization of Oily Skin. Frontiers in Physiology, 2019. 10.doi:10.3389/fphys.2019.00254

4. DRAELOS ZD, et al. The effect of $2 \%$ niacinamide on facial sebum production. Journal of Cosmetic and Laser Therapy. 2006; 8: 96-101.

5. DRESSLER D, et al. Botulinum toxin - Mechanisms of action. Arq Neuropsiquiatr 2005; 63 (1):180-185.

6. EICHENFIELD LF, et al. Perspectives on therapeutic options for acne: an update. Seminars in Cutaneous Medicine and Surgery, 2010; 29, p. 13-16.

7. FERNANDES D. Minimally Invasive Percutaneous Collagen Induction. Oral and Maxillofacial Surgery Clinics of North America, 2005; 17(1), 51-63.

8. HASSUN KA. Acne: etiopatogenia. An bras Dermatol, Rio de Janeiro, 2000. 75(1):7-15, jan./fev.

9. JACOBS SW, CULBERTSON EJ. Effects of Topical Mandelic Acid Treatment on Facial Skin Viscoelasticity. Facial Plast Surg. 2018; 34 (6): 651-656.

10. KHAN H, et al. Assessment of Combined Ascorbyl Palmitate (AP) and Sodium Ascorbyl Phosphate (SAP) on Facial Skin Sebum Control in Female Healthy Volunteers. Drug Research, 2016; 67(01), 52-58.

11. KIM B, et al. Sebum, acne, skin elasticity, and gender difference - which is the major influencing factor for facial pores? Skin Research and Technology, 2011; 19(1), e45-e53.

12. LEE D, et al. Sebocytes Express Functional Cathelicidin Antimicrobial Peptides and Can Act to Kill Propionibacterium Acnes. Journal of Investigative Dermatology, 2008 128(7), 1863-1866.

13. LI ZJ, et al. Regulation of lipid production by acetylcholine signalling in human sebaceous glands. J Dermatol Sci. 2013; 72(2): 116.

14. LI X, et al. A review of the role of sebum in the mechanism of acne pathogenesis. Cosmet Dermatol. 2017; 00:1-6.

15. LOSIFIDIS C, GOUTOS I. Percutaneous collagen induction (microneedling) for the management of non-atrophic scars: literature review. Scars, Burns \& Healing, 2019; 5: 205951311988030.

16. MADAN RK, LEVITT J. A review of toxicity from topical salicylic acid preparations. Journal of the American Academy of Dermatology, 2014; 70(4), 788-792.

17. MAHMOOD T, et al. Outcomes of $3 \%$ green tea emulsion on skin sebum production in male volunteers. Bosn $\mathrm{J}$ Basic Med Sci. 2010; 10(3): 260-264.

18. MIN P, et al. Sebum production alteration after botulinum toxin type A injections for the treatment of forehead rhytides: a prospective randomized double-blind dose-comparative clinical investigation. Aesthetic Surg J. 2015; 35(5): 600.

19. MURILLO RM. Luz pulsada intensa: aplicaciones en dermatologia. Rev Hosp Jua Mex 2011; 78(4): $240-243$.

20. OHISHI T, et al. Anti-inflammatory Action of Green Tea Antiinflamm Antiallergy Agents Med Chem. 2016;15(2):74-90.

21. ROH M. Sebum output as a factor contributing to the size of facial pores. British Journal of Dermatology, 2006; 155(5), 890894.

22. SARKAR R, et al. Comparative Evaluation of Efficacy and Tolerability of Glycolic Acid, Salicylic Mandelic Acid, and Phytic Acid Combination Peels in Melasma. Dermatologic Surgery, 2016; 42(3): 384-391.

23. SHAR AR. Use of intradermal botulinum toxin to reduce sebum production and facial pore size. J Drugs Dermatol. 2008; 7(9): 847-50.

24. SOMA Y, et al. Moisturizing effects of topical nicotinamide on atopic dry skin. International Journal of Dermatology 2005; 44 : 197-202.

25. STEINSAPIR KD, et al. Cosmetic Microdroplet Botulinum Toxin A Forehead Lift. Ophthalmic Plastic and Reconstructive Surgery, 2015; 31(4): 263-268.

26. TANNO O, et al. Nicotinamide increases biosynthesis of ceramides as well as other stratum corneum lipids to improve the epidermal permeability barrier. British Journal of Dermatology. 2000; 143: 524 \pm 531 .

27. VARGAS DCO, PERDÓMO HAG. Efficacy of botulinum toxin A for the treatment of bladder pain syndrome: A systematic review. Actas Urológicas Españolas (English Edition), 2018; 42(3): 152-162.

28. VAYALIL PK, et al. Green Tea Polyphenols Prevent Ultraviolet Light-Induced Oxidative Damage and Matrix Metalloproteinases Expression in Mouse Skin. Journal of Investigative Dermatology, 2004; 122(6): 1480-1487.

29. VOEGELI R, et al. Facial skin mapping: from single point bio-instrumental evaluation to continuous visualization of skin hydration, barrier function, skin surface $\mathrm{pH}$, and sebum in different ethnic skin types. International Journal of Cosmetic Science, 2019. doi:10.1111/ics.12562.

30. WOHLRAB J, et al. Niacinamide - Mechanisms of Action and Its Topical Use in Dermatology. Skin Pharmacology and Physiology, 2014; 27(6): 311-315.

31. ZAHOOR M, et al. Isolation of quercetin and mandelic acid from Aesculus indica fruit and their biological activities. BMC Biochem. 2019; $1: 5$. 